\title{
Toz Yatak Füzyon Birleştirme (PBF) Eklemeli İmalatta, Destek Yapıların Parçalardaki Kalıntı Gerilmeler Açısından İncelenmesi
}

\author{
${ }^{* 1}$ Mevlüt Yunus Kayacan, ${ }^{2}$ Nihat Yilmaz \\ ${ }^{1,2}$ Isparta Uygulamalı Bilimler Üniversitesi, Teknoloji Fakültesi, Makina ve İmalat Müh. Böl.
}

\section{Özet}

$\mathrm{Bu}$ çalışma toz yatak füzyon birleştirme tipi eklemeli imalat sistemlerinden olan DMLS ile parça üretiminde karşılaşılan sorunların tespiti üzerine gerçekleştirilmiştir. Metal eklemeli imalatta yaygın olarak tercih edilen Ti6A14V tozlar ile parça imalatı esnasında karşılaşılan problemler araştırılmıştır. Araştırma sonucunda, imalat esnasında parçalarda meydana gelen hataların en önemli nedenleri imalat esnasında oluşan iç gerilmeler ve parça üzerindeki deformasyonlar olarak tespit edilmiştir. Çalışma kapsamında örnek bir parçanın farklı destek yapıları kullanılarak imal edilmesi durumu sonlu elemanlar metodu ile analiz edilmiştir. Kaldıraç tipi bir parça literatür doğrultusunda tasarlanmıştır. 5 farklı destek yapısı analizlerde kullanılmıştır. Parçada oluşan iç gerilmeler ve deformasyonlar incelenmiştir. Destek yapı tipinin parçada oluşan iç gerilmelere ve deformasyonlara olan etkisi Ti6Al4V malzemeler için tespit edilmiştir.

Anahtar Kelimeler: eklemeli imalat, toz yatak birleştirme, DMLS, kalıntı gerilme, Ti6Al4V

\begin{abstract}
This study has been carried out on DMLS which is one of the powder bed fusion type additive manufacturing systems to detect problems in parts production. Ti6Al4V powders, which are widely preferred in metal additive manufacturing, have been investigated for problems encountered during manufacturing. As a result of research, the most important causes of faults in the parts during manufacturing have been determined as internal stresses and deformations on the part during manufacturing. In the scope of the study, the case of manufacturing a sample part using different support structures was analyzed by the finite element method. A lever-type part is designed in accordance with the literature. Five different support structures were used in the analyzes. Internal stresses and deformations in the part have been investigated. The effect of the support structure type on the internal stresses and distortions occurring in the part was determined for Ti6Al4V materials.
\end{abstract}

Key Words: Additive manufacturing, Powder bed fusion, DMLS, residual stress, Ti6Al4V

\section{Giriş}

Toz Yatak Füzyon Birleştirme (PBF) yöntemi eklemeli imalatın temel yöntemlerinden bir tanesidir. Bu yöntem Toz haldeki malzemeler katmanlar halinde bir tabla üzerine serilmektedir. Her katman kontrollü bir şekilde yalnızca gerekli bölgelerin lazer ile ergitilerek işlenir. Bu işlemler ardı ardına devam ederek sonunda parçayı meydana getirir [1,2].

Parça üretimi esnasında çeşitli parametreler parça kalitesini etkilemektedir. Bunlar Makine parametreleri, malzeme özellikleri, imalat ortamı şartları ve parça tasarımına bağlıdır. Makine parametreleri; katman kalınlığı, tarama hızı, tarama mesafesi, lazer odak çapı, lazer gücü, 
tarama stratejisi vb. olarak sıralanabilir. Malzeme özellikleri malzemenin her türlü fiziksel ve kimyasal özellikleri olabilir. İmalat ortamı sıcaklık ve atmosfer gibi etkenleri barındırır. Parça tasarımı ise parçanın geometrisi, tablaya konumlandırılması gibi çeşitli parametreleri kapsar [3$5]$.

Parça tasarımları parçanın kalitesi için önemli olduğu kadar hatasız "imalat kabiliyeti" açısından büyük önem taşımaktadır. Tasarımlarda ilk etken parça geometrisidir. Tablaya göre eğim açısı, parça boyutları, eğrisellik, prizmatiklik, silindiriklik, küresellik, ince cidarlılık ve kafes yapılı olma gibi birçok farklı tasarım tipi olabilir. Tüm bunlar geometrik kriterler olarak da ele alınabilir. İkinci tasarım etkeni ise destek yapılar ile devreye girmektedir. Destek yapılar parçanın gerekli bölgelerinin imalat esnasında hataya maruz kalmaması için tasarlanan parçalardır. Yalnızca parça imal edilene kadar etkin rol üstlenirler. İmalat sonrasında tabladan ve parçadan ayrıştırılması gerekir [6,7].

Destek yapılar parçanın zayıf olduğu ve imalat esnasında parçanın sarkma yapması olası bölgelerde kullanılırlar. Zayıf olan bölgelerin altından veya etrafından koruyucu ve destekleyici nitelikte olarak bu yapılar kullanılabilir. Sarkma olan yerlerde ise alttan desteklemek suretiyle görev yaparlar. Parçaların sarkması durumu parça yüzeylerinin düşey eksenle $45^{\circ}$ 'den daha fazla eğim açısı yapması sonucu meydana gelir. Bu durumlarda destek yapısı kullanmak kaçınılmaz bir hale gelecektir[8].

Destek yapıları kullanılacak olan yerlere ve parça geometrisine bağlı olarak değişim gösterebilir. Parçanın daha yüksek oranda desteklenmesi gereken durumlarda daha yoğun ve mukavemetli destek yapıların kullanılması gerekirken daha düşük yüklemelere maruz kalan bölgelerde ise düşük mukavemetli ve daha az yoğun tasarımlar yapılabilmektedir. Yaygın olarak tercih edilen tasarımlar Hacimsel, çizgisel, çevresel, ağsı ve blok tipi destek yapılarıdır. $\mathrm{Bu}$ destek yapılarından hacimsel olan tam dolu bir parça iken diğer destek yapılar daha az malzeme kullanılarak tasarlanmaktadır. Eklemeli imalatın önemli avantajlarından bir tanesi olan düşük malzeme israfı nedeniyle hacimsel destek yapılardan daha ziyade diğer destek yapıların kullanılması beklenir. Böylece daha düşük maliyetli parçalar üretilecek aynı zamanda da imalat sonrasında destek yapıların tabladan ve parçadan ayrıştırılması işlemi daha az zaman ve emek isteyecektir [9-10].

Günümüzde destek yapıların kullanımı daha çok tecrübelere ve rastlantısal kararlara bağlı olarak verilmektedir. Ancak araştırmalar sonucunda destek yapı tasarımlarının avantaj/dezavantajları ve kullanım yerleri tespit edilmelidir. Böylece hata oranı daha düşük, düşük maliyetli parça üretimi ihtimali artacaktır. Avantaj ve dezavantajların tespiti noktasında parçada meydana gelen iç/kalıntı gerilmeler ve çarpılma/deformasyon durumları incelenmelidir. Çünkü imalat esnasında meydana gelen hataların büyük bölümü bunlardan kaynaklanmaktadır [11,12].

\section{Materyal ve Yöntem}

EOS M280 DMLS (Doğrudan Metal Lazer Sinterleme) makinesi ile imalat yapılması durumu analiz edilmiştir. Tabla boyutu 280*280*20 mm'dir. Lazer gücü $175 \mathrm{~W}$, tarama hızı $1150 \mathrm{~mm} / \mathrm{s}$, tarama mesafesi $0,1 \mathrm{~mm}$, lazer odak çap1 $0,15 \mathrm{~mm}$ ve katman kalınlığ $10,03 \mathrm{~mm}$ olarak ayarlanmıştır. Enerji yoğunluğu 50,73 J/mm3 olarak hesaplanmıştır. Malzeme Ti6A14V titanyum alaşımdır. 
Bu durumda "Simufact Additive" programında şekil değişimi ve kalıntı gerilme hesaplamaları için kullanılacak olan iç gerilme değerleri; $\varepsilon_{\mathrm{x}}=-0,00581473, \varepsilon_{\mathrm{y}}=-0,0026075, \varepsilon_{\mathrm{z}}=-0,0242824$ olarak hesaplanmıştır. Mesh işlemi için $0.75 \mathrm{~mm}$ boyutunda tetragonal mesh tipleri tercih edilmiştir. İmalat sonrasında 1sıl işlem uygulanmamış ve imalat esnasında oluşan iç/kalıntı gerilmeler giderilmemiştir. Böylece gerilmelerin miktarı, konumları ve çarpılma üzerindeki etkileri anlaşılmıştır.

Daha önce yapılan çalışmalar doğrultusunda destek yapıların uygulanacağı parçanın tasarımı yapılmıştır [13]. Kaldıraç tipi bir parça tasarlanmıştır. Böylece kaldıracın tablaya temas etmeyen yan kısımlarında sarkmalar oluşması kesindir. Sonlu elemanlar analizleri sonucunda net bir biçimde kenar bölgelerdeki çarpılma tespit edilebilecektir. Tasarım destek yapılar kullanılarak dahi hatasız olarak çok zor imal edilebilecek bir parçadır. Tasarlanan parça şekil 1 'de gösterilmiştir.

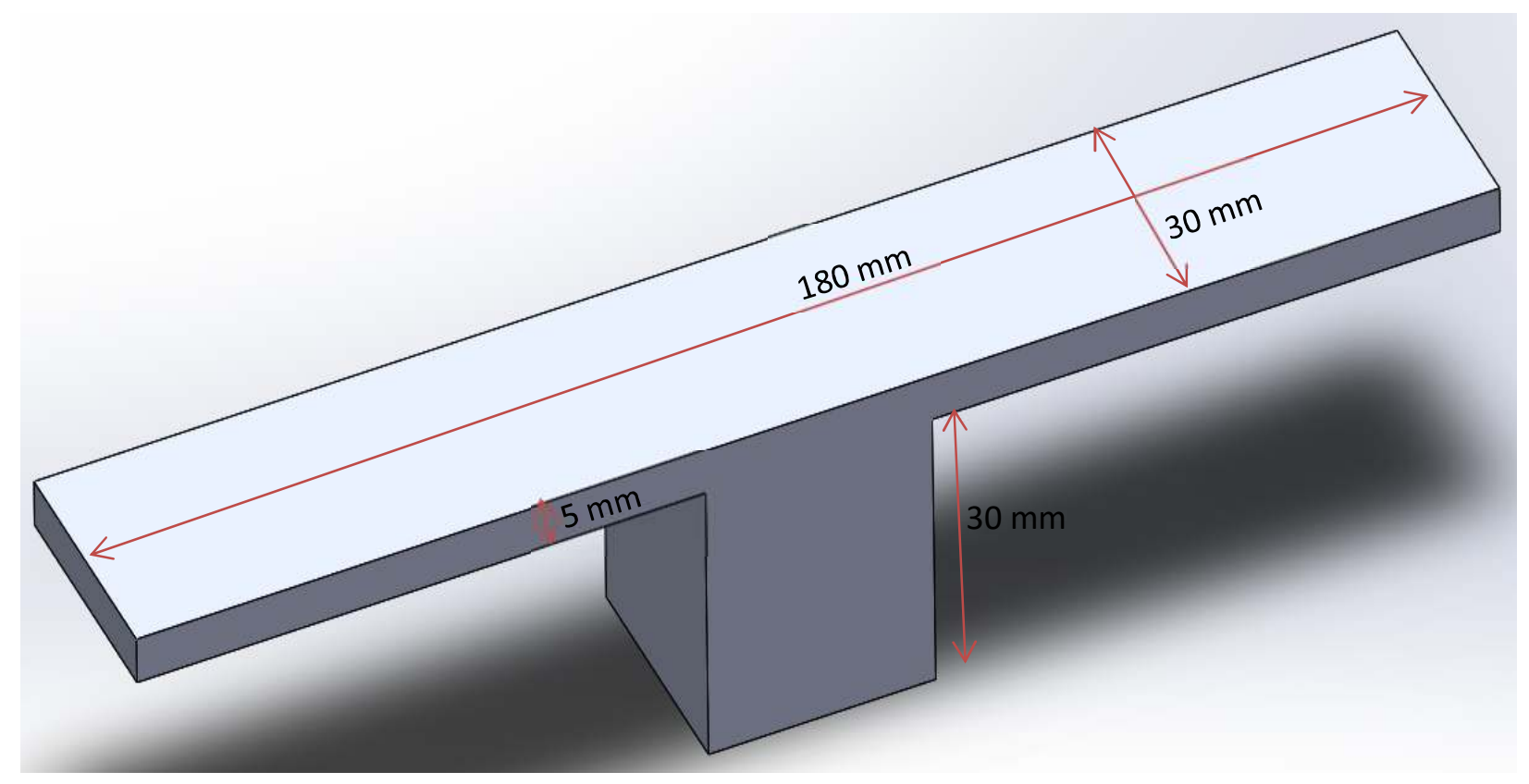

Şekil 1. Analizlerde kullanılan kaldıraç tipi parça tasarımı

Belirtildiği üzere şekil 1'de görülen parçanın doğrudan bu şekilde imal edilmesi olanaksızdır. Mutlaka sarkmalar ve çarpılmalar oluşacak ve parçada toleranslar dışında hatalar meydana gelecektir. Bu nedenle bu bölgelere destek yapılarak uygulanmalıdır. Destek yapı tasarımları "Materalise Magics" programı kullanılarak gerçekleştirilmiştir. Kaldıracın altı boş olan kısımlarına destekler yerleştirilmiştir. Şekil 2'de destek yapılar ve kaldıracın sol kolu altındaki yerleşimi görülmektedir. 


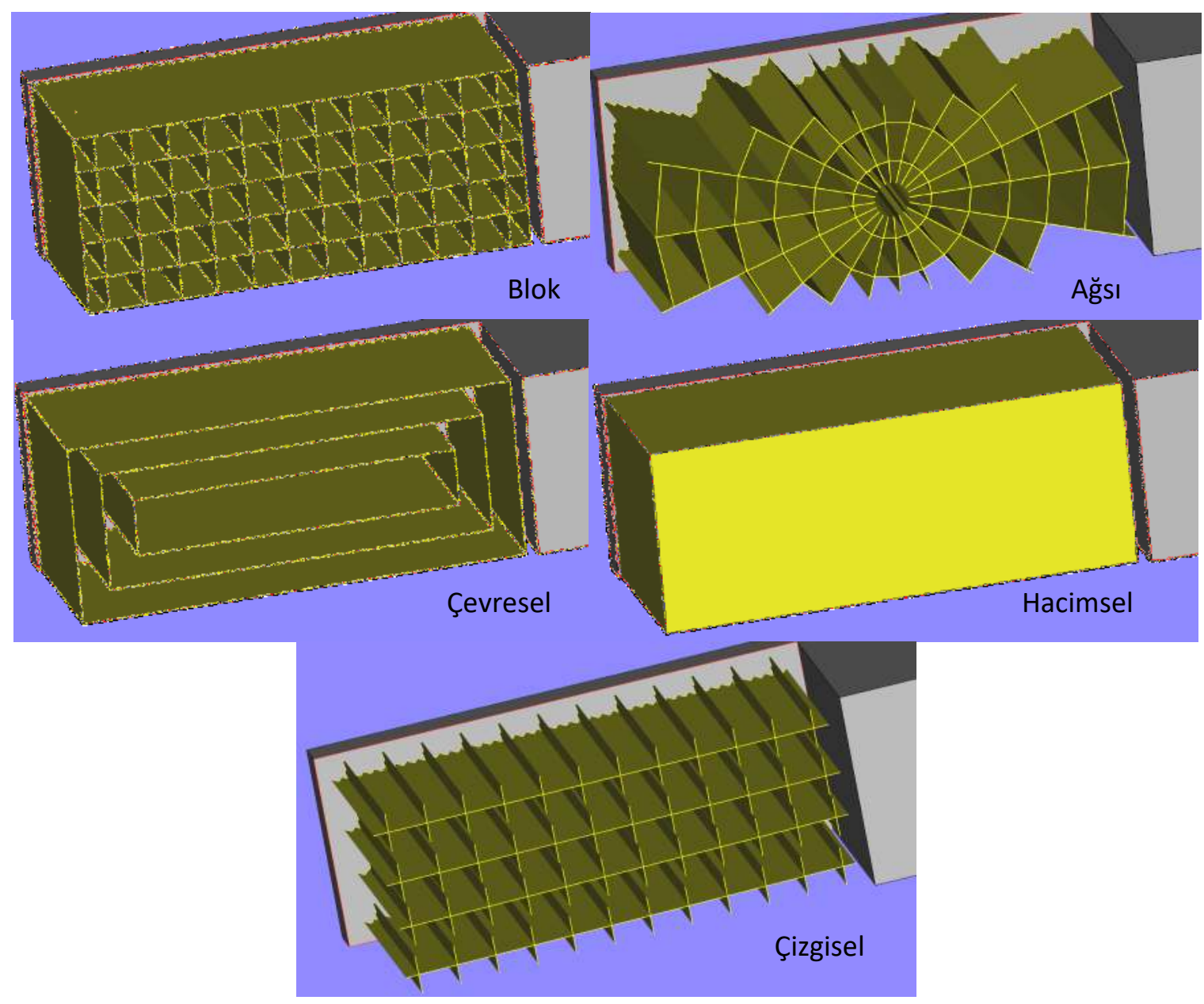

Şekil 2. Kaldıracın sol kolu ve altına uygulanmış destek yapı tasarımları

Destek yapılar kaldıraç kolunu alt yüzeyi boyunca destekleyici görev yapmaktadırlar. $\mathrm{Bu}$ destekleme hem kaldıraç kolunun düşük mukavemet etkisiyle ve yer çekimi etkisiyle aşağıya sarkmasını engelleyici hem de kaldıraç kolundaki iç gerilmelerin minimum düzeyde çarpılmaya oluşumunun önlenmesi şeklindedir. Şekil 2'de görüldüğü üzere blok, hacimsel, çizgisel, çevresel ve ağsı yapıdaki destek yapılar analizlere dahil edilmiştir. Analiz sonuçları kalıntı gerilmeler ve çarpılmalar olarak elde edilmiştir.

\section{Bulgular ve Tartışma}

Analizler kapsamında 5 farklı destek yapısı kullanılarak kaldıraç tasarımlı parça imalatı gerçekleştirilmiştir. Sonuçlar 3 aşamalı olarak ele alınmıştır. İlki imalatı tamamlanmış parça ve destek yapıları, ikincisi parça ve destek yapılarının tabladan kesilmesi sonrası durum, sonuncuda ise parçadaki destek yapıların ayrıştırılması işlemi tamamlanmıştır. Tüm analiz sonuçları kalıntı gerilmeler $(\mathrm{MPa})$ ve çarpılma miktarı $(\mathrm{mm})$ cinsinden ele alınmıştır. Tablo 1'de elde edilen maksimum kalıntı gerilme ve çarpılma miktarı değerleri gösterilmiştir. 
Tablo1. Elde edilen maksimum kalıntı gerilme ve şekil değişimi verileri

\begin{tabular}{|c|c|c|c|}
\hline \multicolumn{4}{|c|}{ İmalat Sonrası (ek işlem yok) } \\
\hline & $\begin{array}{l}\text { Destek } \\
\text { Yapıs1 }\end{array}$ & $\begin{array}{c}\text { Kalıntı } \\
\text { Gerilme } \\
(\mathrm{MPa})\end{array}$ & $\begin{array}{c}\text { Çarpılma } \\
\text { Miktarı }(\mathrm{mm})\end{array}$ \\
\hline \multirow{5}{*}{$\begin{array}{c}\text { İmalat } \\
\text { Sonrası (ek } \\
\text { işlem yok) }\end{array}$} & Blok & 1285 & 0,26 \\
\hline & A 乌gs1 & 1209 & 0,49 \\
\hline & Çizgisel & 1189 & 0,39 \\
\hline & Hacimsel & 1189 & 0,27 \\
\hline & Çevresel & 1182 & 0,26 \\
\hline \multirow{5}{*}{$\begin{array}{c}\text { Parçanın ve } \\
\text { destek } \\
\text { Yapıların } \\
\text { Tabladan } \\
\text { Kesilmesi } \\
\text { Sonrası }\end{array}$} & Blok & 1171 & 1,1 \\
\hline & A $\breve{g s} 1$ & 1178 & 1,58 \\
\hline & Çizgisel & 1170 & 1,64 \\
\hline & Hacimsel & 1161 & 1,05 \\
\hline & Çevresel & 1171 & 2,02 \\
\hline \multirow{5}{*}{$\begin{array}{c}\text { Destek } \\
\text { Yapıların } \\
\text { Parçadan } \\
\text { Temizlenmesi } \\
\text { Sonrası }\end{array}$} & Blok & 1171 & 1,25 \\
\hline & A ̆gs1 & 1179 & 2,28 \\
\hline & Çizgisel & 1151 & 2,56 \\
\hline & Hacimsel & 1170 & 1,19 \\
\hline & Çevresel & 1172 & 2,58 \\
\hline
\end{tabular}

Elde edilen sonuçlara göre imalat sonrasında en yüksek kalıntı gerilme değerlerine ulaşılmış ancak çarpılma miktarları sınırlı düzeyde seyretmiştir. Ancak parçanın tabladan kesilmesinden sonra kalıntı gerilmeler bir miktar azalmış ve çarpılma miktarları ciddi oranda artış göstermiştir. $\mathrm{Bu}$ artış miktarı ortalama yaklaşık olarak 5 kat kadardır. Destek yapıların parçadan ayrıştırılması işlemi sonrasında ise yaklaşık olarak 2 kat civarında bir çarpılma miktarı görülmektedir. Yani her mekanik işlem sonucunda bir çarpılma oluşumu söz konusudur. $\mathrm{Bu}$ durum fiziksel olarak gerilim gevşemesi olarak bilinmektedir. Parçadaki iç gerilmelerin mekanik etkiler sonucunda kalıcı şekil değişimine sebebiyet vermesi olarak yorumlanmaktadır.

Çalışmada elde edilen diğer sonuçlara göre en düşük çarpılma miktarı blok ve hacimsel tip destek yapılarında elde edilmiştir. En yüksek çarpılma miktarları ise çizgisel ve çevresel destek yapılarında elde edilmiştir. Bu noktada dikkat edilmesi gerek bir durum da çarpılmaların meydana geldiği konumlardır. Çarpılmanın düşük olduğu blok ve hacimsel destek yapılı imalatlarda deformasyonlar kaldıracın tablaya temas eden sütun bölgesindedir. Ancak çarpılmanın yüksek olduğu çizgisel ve çevresel destek yapılı parçalarda ise en yüksek şekil değişimleri kaldıracın kollarının bittiği bölgelerde görülmektedir. Şekil 3'te bu durum açıklanmıştır. 


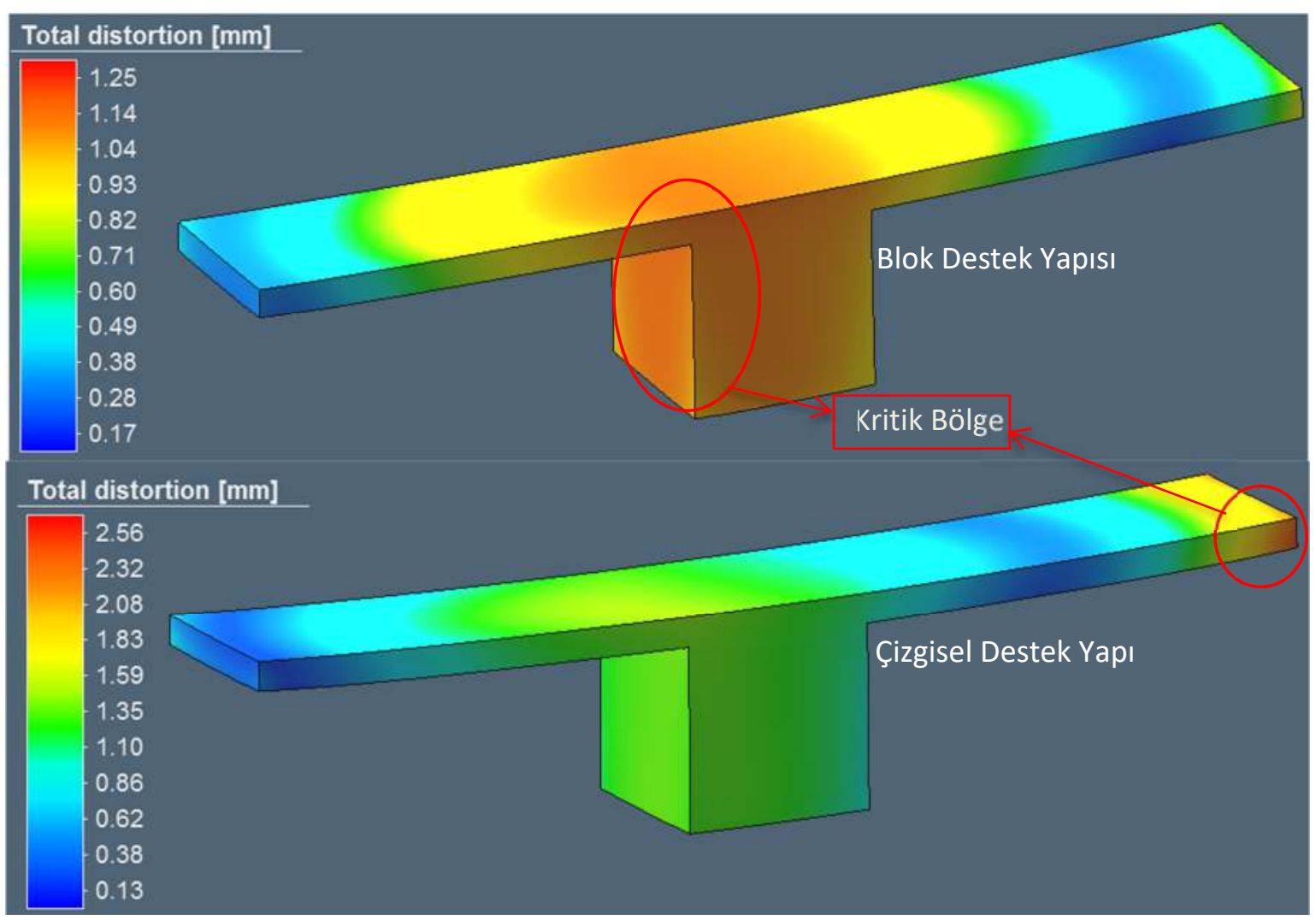

Şekil 3. Yüksek çarpılma (çizgisel destek) ve düşük çarpılma (blok destek) durumlarında deformasyon dağglımı

Gerilme dağılımı ise hem yüksek çarpılma oluşan hem de düşük çarpılma oluşan durumlarda birbirine benzer şekilde dağılım göstermektedir. Maksimum gerilme dağılımı kaldıracın tablaya temas eden sütun kısmında konumlanmıştır. Burada tüm işlemler sonrasında yığılma gösterdiği kısımlar ise kenar bölgelerin orta kısımları olarak karşımıza çıkmıştır. Ancak başlangıçta bu yığılma kenarların tabla ile temas ettiği bölgelerde görülmektedir. Bu değişim yine gerilim gevşemesi olayının bir sonucudur. Kesilme esnasında tablaya temas eden bölgelerde bir gerilim düşümü olmuştur. Şekil 4'te tüm işlemler sonrası elde edilen gerilme dağılımı gösterilmiştir.

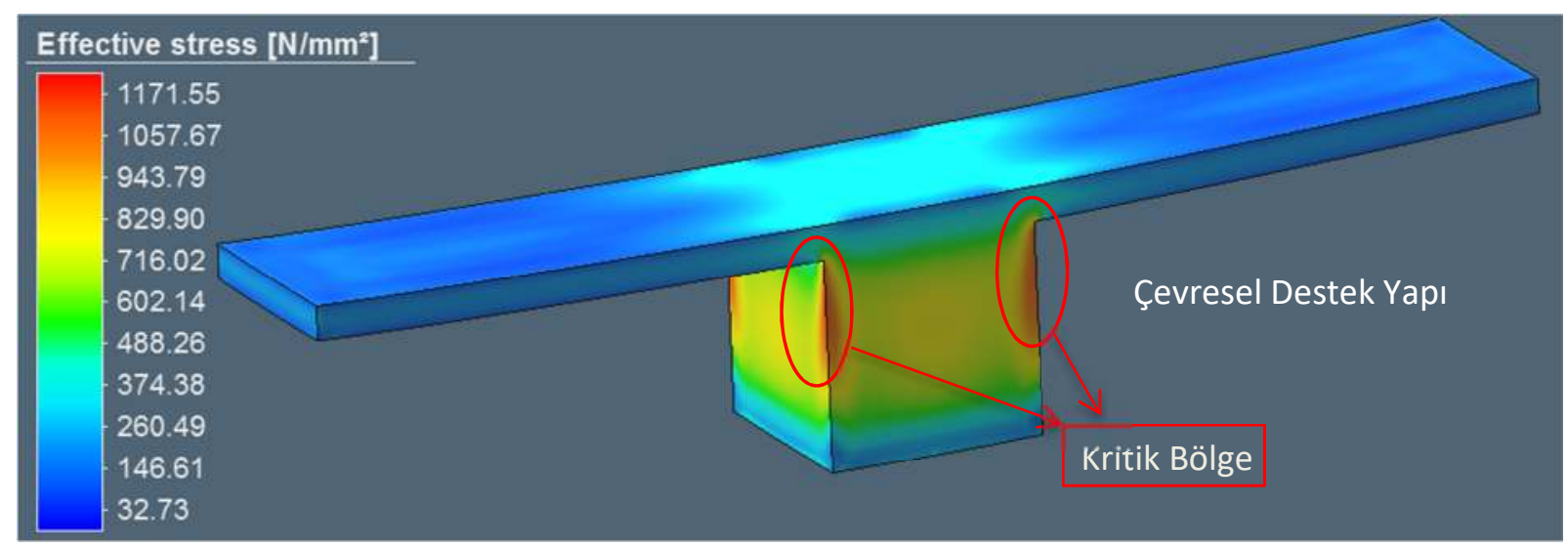

Şekil 4. Tüm işlemler tamamlandıktan sonra çevresel destek yapılı imalat örneği üzerinden tüm durumlarda geçerli gerilme dağılımı 
Normalde imalat sonrasında herhangi bir ilave işlem (kesme, destekleri ayrıştırma vb.) yapılmadan önce parçalar gerilim giderme tavlaması işlemine tabi tutulmaktadır. Bu nedenle bizim için asıl dikkat edilmesi gereken değerler Tablo 1'de "İmalat Sonrası (ek işlem yok)" ile ifade edilen kısımlardır. Buraya göre blok, hacimsel ve çevresel destek yapı kullanımının en uygun sonuçları verdiği görülmektedir. Ancak burada dikkat edilmesi gereken bir durum daha vardır. Eğer imal edilen parça daha büyük boyutlarda olursa veya daha ince kesitli tasarımlar barındırırsa parçanın meydana gelen iç gerilmelere mukavemet göstermesi mümkün olamayabilir. Bu nedenle tabladan kesilme ve desteklerin ayrıştırılması durumları da göz önünde bulundurulmalıdır. Çünkü imalat esnasında istenmeyen bir şekilde gerilme gevşemesi oluşursa parça çok daha yüksek miktarlarda çarpılacaktır. Hatta çatlak ilerlemesi şekilde çok daha ciddi sorunlar da oluşabilir.

\section{Sonuçlar ve Öneriler}

Yapılan çalışma ile DMLS ile metal eklemeli imalatın temel bileşenlerinden bir tanesi olan destek yapılar ele alınmıştır. Çalışma sonucunda kritik bir geometriye sahip olan kaldıraç tasarımına sahip bir parça üzerinde çalışılmıştır. Bu kritik durumda en iyi sonuçları veren destek yapılar belirlenmiştir. Elde edilen bulgulara sonuçlar şu şekilde yorumlanmıştır:

- En uygun destek yapısı tasarımları imalat sonrasında ilave işlem uygulanman önce 0,26 mm çarpılma oluşan blok, hacimsel ve çevresel destek yapılardır. Ancak hacimsel destek yapılarda malzeme sarfiyatı artmakta ve maliyetler artmaktadır. Çevresel destek yapılarda ise 1 sıl işlem uygulanmaksızın ilave işlemler uygulanması durumlarında çarpılma miktarı çok artmaktadır. Bu nedenle her durum makul sonuçlar vermesinden dolayı blok tipi destek yapılar ön plana çıkmaktadır.

- Maksimum çarpılmalar kaldıraç kollarının uç kısımlarında oluşmaktadır. Bu kısımların diğer kısımlardan farklı olarak daha yüksek mukavemet gösterecek şekilde destek yapılarla takviye edilmesi düşünülebilir. Örneğin sadece bu kısımlar için hacimsel destek yapılar tercih edilebilir.

$\mathrm{Bu}$ çalışmanı devamı olarak, gerçek imalatlar ile analiz sonuçlarının kıyaslanması durumları çalışılmalıdır. Böylece çalışmadaki öngörülerin doğruluğu test edilebilmiş olacaktır.

\section{Teşekkür}

Yazarlar Netform şirketine "MSC Simufact Additive" isimli paket programın "trial licence" şeklinde kullanımını sağladıkları için teşekkür eder.

\section{Kaynaklar}

[1] Everton SK, Hirsch M, Stravroulakis P, Leach RK, Clare AT. Review of in-situ process monitoring and in-situ metrology for metal additive manufacturing. Mater. Des. 2016; 95, 431-445.

[2] Frazier WE. Metal additive manufacturing: A review. J. Mater. Eng. Perform. 2014; c. 23, 6, 1917-1928. 
[3] Ning Y. Process Parameter Optimization for Direct Metal Laser Sintering ( DMLS ). (Electronic Thesis or Dissertation). Retrieved from https://core.ac.uk/download/pdf/48628004.pdf

[4] Ningy Y, Fuhy JYH, Wongy YS, Lohy HT. An intelligent parameter selection system for the direct metal laser sintering process. Int. J. Prod. Res 2004; c. 42, 1, 183-199.

[5] Paul, R. (). Modelling and Optimization of Powder Based Additive Manufacturing (AM) Processes. (Electronic Thesis or Dissertation). Retrieved from https://etd.ohiolink.edu/

[6] Poyraz Ö, Yasa E, Akbulut G, Orhangul A, Pilatin S. Investigation of support structures for direct metal laser sintering (DMLS) of IN625 parts. In Proceedings of the Solid Freeform Fabrication Symposium, Austin, Texas, USA, 2015, pp. 560-574.

[7] Das P, Chandran R, Samant R, Anand S. Optimum part build orientation in additive manufacturing for minimizing part errors and support structures. Procedia Manufacturing 2015; 1: 343-354.

[8] Calignano F. Design optimization of supports for overhanging structures in aluminum and titanium alloys by selective laser melting. Materials \& Design 2014; 64: 203-213.

[9] Bertol LS, Júnior WK, da Silva FP. Aumund-Kopp, C., Medical design: direct metal laser sintering of Ti-6Al-4V. Materials \& Design 2010; 31.8: 3982-3988.

[10] Atzeni E, Salmi A. Study on unsupported overhangs of AlSi10Mg parts processed by Direct Metal Laser Sintering (DMLS). Journal of Manufacturing Processes 2015; 20: 500-506.

[11] Mercelis P, Kruth JP. Residual stresses in selective laser sintering and selective laser melting. Rapid prototyping journal 2006; 12.5: 254-265.

[12] Yadroitsev I, Yadroitsava I. Evaluation of residual stress in stainless steel 316L and Ti6Al4V samples produced by selective laser melting. Virtual and Physical Prototyping 2015;10.2: 67-76.

[13] Zaeh MF, Branner G. Investigations on residual stresses and deformations in selective laser melting. Production Engineering 2010; 4.1: 35-45. 